\title{
Cytoreductive Stereotactic Body Radiotherapy with Tyrosine Kinase Inhibitors for Intrathoracic Oligoprogressive EGFR-mutated Lung Cancer
}

\section{Anupam Rishi ( $\square$ anupam.rishi@moffitt.org ) \\ Moffitt Cancer Center https://orcid.org/0000-0001-5258-9601}

\section{Steven Sun}

USF Health Morsani College of Medicine

Ahmad M Karimi

Moffitt Cancer Center

Austin J Sim

Moffitt Cancer Center

Michael Shafique

Moffitt Cancer Center

Andreas N Saltos

Moffitt Cancer Center

Jhanelle E Gray

Moffitt Cancer Center

Bradford A Perez

Moffitt Cancer Center

Thomas J Dilling

Moffitt Cancer Center

Stephen A Rosenberg

Moffitt Cancer Center

\section{Research}

Keywords: SBRT, EGFR, Tyrosine kinase inhibitor, Oligoprogression, Outcome

Posted Date: December 13th, 2021

DOI: https://doi.org/10.21203/rs.3.rs-1132236/v1

License: (c) (1) This work is licensed under a Creative Commons Attribution 4.0 International License.

Read Full License 


\section{Abstract}

Background: Epidermal growth factor receptor (EGFR) mutated non-small cell lung cancer (NSCLC) shows an impressive initial response to EGFR tyrosine kinase inhibitors (EGFR-TKI). However, resistance invariably develops, commonly involving the site of initial gross disease. Cytoreductive stereotactic body radiotherapy (SBRT) for thoracic oligoprogressive disease (OPD) may effectively delay progression through EGFR-TKI therapy.

Methods: From a prospectively maintained IRB-approved institutional registry, we identified 23 patients consecutively treated between 2011-2019 with thoracic SBRT and received EGFR-TKI within 6-months of SBRT. Radiographic progression-free (PFS) and overall survival (OS) were estimated using Kaplan-Meier analysis. Toxicity and patient-reported Edmonton Symptom Assessment Scale (ESAS) scores were reviewed.

Results: Median follow-up after SBRT was 20-months (range, 4-100), and the median age was 68-years (range, 33-89). Most patients were females ( $n=21 ; 91.3 \%)$. RT dose was 50-60 Gy in 5-10 fractions. EGFRTKI administered were erlotinib, osimertinib and gefitinib in 15, 5, and 3 patients, respectively. Median PFS and OS following SBRT were 8-months and 31-months, respectively. 1-year PFS and OS were $34.8 \%$ and $78.3 \%$. The median duration of EGFR-TKI therapy was 26-months (1-91). Most patients progressed in new distant sites, most commonly bones $(n=5 ; 21.7 \%)$ and distant lung $(n=4 ; 17.4 \%)$, with only $2 / 23$ patients having initial progression within the SBRT field. Grade-2 pneumonitis $(n=2)$ and rib fracture $(n=1)$ were noted radiation-related toxicities. Dominant ESAS symptoms were fatigue (21.7\%), pain (8.7\%), and loss of appetite (8.7\%).

Conclusions: For EGFR-mutated NSCLC patients with thoracic OPD on EGFR-TKI, SBRT was well tolerated, resulted in changes in subsequent patterns of failure, lengthened PFS, and prolongs the duration of initial TKI therapy.

\section{Introduction}

Multiple oncogenic driver mutations, including epidermal growth factor receptor (EGFR) have been identified to play a vital role in the oncogenesis of NSCLC [1]. Their discovery led to the development of targeted therapies such as tyrosine kinase inhibitors (TKIs), that changed the landscape of systemic therapy for advanced NSCLC. However, following initial impressive response to EGFR-TKIs, acquired resistance is inevitable after 6-13 months of therapy initiation and remains the major challenge in achieving long-term control [2-4].

Traditionally, even a single site of metastasis was considered incurable, and treatment was palliative. However, oligometastatic disease ( $\leq 5$ metastatic sites) treatment paradigm of NSCLC has recently shifted. Local cytoreductive therapy (LCT) has shown to improve progression free survival (PFS) and overall survival (OS) for oligometastatic NSCLC [5-7]. Although progression is often inevitable, progressive metastatic disease limited to few cancer deposits i.e. oligo-progressive disease (OPD) may 
harbor unique biologic subclones that confers resistance to initial line of therapy. Pattern-of-failure analyses in all-comer lung cancer patients on systemic therapy demonstrated that progression at intrathoracic disease site is the predominant site of initial failure [8-11]. A recent study showed that the majority of EGFR-mutant patients treated with osimertinib developed progressive disease initially involving the original site of gross disease and were amenable to stereotactic body radiotherapy (SBRT) [9]. Ablative treatment to these lesions may act synergistically with EGFR-TKIs to eradicate the dedifferentiated resistant subclones, confer overall treatment sensitivity, and allow patients to continue EGFR-TKIs for a prolonged duration.

SBRT offers a radiobiological advantage of delivering ablative radiation dose to the tumor to achieve a high rate of durable control, that could potentially result in additional clinical benefit of targeted therapy [12-14]. A recent study assessed upfront SBRT combined with targeted therapy in treatment naïve oligometastatic patients, however, the effectiveness of SBRT in thoracic OPD patient that progressed through EGFR-TKI therapy is still investigational [15]. We present our long-term experience, which to the best of our knowledge is one of the largest data evaluating role of SBRT in EGFR-mutated NSCLC with limited intrathoracic oligoprogression through EGFR-TKI therapy. We hypothesized that addition of SBRT in this patient group is safe, lead to improved PFS compared to historical data for patients receiving EGFR-TKI alone, and may change subsequent patterns of failure.

\section{Material And Methods}

\section{Patient Population:}

We collected data from a prospectively-maintained IRB approved registry which include 1764 consecutive patients treated with lung SBRT. Eligible patients were $>18$ years, with Karnofsky performance score $>60$, biopsy proven EGFR-mutant NSCLC, had intra-thoracic oligoprogression through EGFR-TKI therapy (1st, 2nd, or 3rd generation) and received thoracic SBRT, defined as 5-10 fractions. Between 06/2010 06/2019, 23 EGFR-mutant NSCLC patients were identified, who received EGFR-TKIs within 6-months of SBRT. Oligoprogression was identified by positron emission tomography (PET) and seen on correlative computed tomography (CT) within 8 weeks before the initiation of SBRT. Patients with non-thoracic disease progression and progression at multiple distant sites were excluded from this study. Patients with brain metastasis who were controlled after excision or stereotactic radiosurgery were included.

\section{Radiation Technique}

Patients were simulated in supine position within a customized immobilization device (Body-fix, Smithers Medical Products Inc., North Canton, $\mathrm{OH}$ ), to ensure daily set-up reproducibility. All patients underwent a treatment planning 4D-CT simulation to consider respiratory motion. Radiotherapy target volumes included the progressing lesion on imaging. The gross tumor volume (GTV) was outlined on lung window with no expansion for microscopic disease. An internal target volume (iGTV) was created to account for 
respiratory motion. The planning target volume was defined as a 3-5 $\mathrm{mm}$ isotropic expansion on the iGTV.

The most common SBRT fractionation was 50-60 Gy in 5 daily fractions at 10 - 12 Gy per fraction. A conservative "SBRT-like" hypo-fractionated regimen (5-7.5 Gy per fraction) was used for lesions near critical structures. Target coverage followed principles of SBRT planning such that $99 \%$ of PTV received a minimum $90 \%$ of the prescription dose. Radiotherapy was planned and delivered with IMRT/VMAT in all cases with daily cone-beam CT image guidance to facilitate accurate targeting. The dosimetry data is outlined in supplemental table 1.

\section{Assessments}

Patients were assessed during SBRT treatment and every 3 months thereafter with CT chest/abdomen, physical examination, and laboratory tests per institutional guidelines. Further evaluation was based on suspicion of progression or toxicity. Patients were followed by thoracic medical oncologist and continued EGFR-TKI until progression or per discretion of medical oncologist. All disease response evaluations were based on Response Evaluation Criteria in Solid Tumor (RECIST) criteria (version 1.1). Brain imaging were performed for patients with brain metastases at baseline or signs for brain metastases. Patient filled ESAS questionnaire at each visit, and toxicity data was collected prospectively. Toxicities were evaluated using the National Cancer Institute's Common Terminology Criteria for Adverse Events (version 5.0).

\section{Statistical Analysis:}

Descriptive statistics were used to describe pre-treatment, treatment, toxicity and dosimetric characteristics. Primary endpoints were radiographic PFS and duration of EGFR-TKI therapy. Time-toprogression were calculated from completion of SBRT to the date when any disease progression was first detected. Survival was calculated from SBRT to the date of death; patients alive at the date of last contact were censored at that time. Actuarial local control rates (LCR), PFS and OS were calculated by the Kaplan-Meier method. Local failure (in-field and marginal) was defined per RTOG SBRT trial definition of progressive consolidation on CT within 1-cm of SBRT field, not consistent with benign radiation-induced changes [16]. The log-rank test and univariable analysis of Cox proportional hazards models were used to evaluate the impact of clinical factors on disease outcome. Multivariable analysis was not performed because of the relatively small number of patients. A p-value of $<0.05$ was considered significant. All levels of significance were 2-sided. Data were analyzed using the statistical software SPSS for Windows (version 24.0, IBM Corp., Armonk, N.Y., USA).

\section{Results}

\section{Patient and treatment characteristics}

The study cohort included 23 patients, with biopsy confirmed lung adenocarcinoma. Patient demographics, disease and treatment characteristics are summarized in Table 1. Most patients were metastatic $(21 / 23,91.3 \%)$, female $(21 / 23,91.3 \%)$ and smoked < 15 pack-years $(15 / 23,65 \%)$. Common 
EGFR mutations were exon $19(n=10)$, exon 20 T790M $(n=8)$ and exon 21 L858R $(n=5)$, with overlapping co-mutations in 9 patients. SBRT was administered for true OPD in 20 patients, while 2 patients had isolated thoracic recurrence, and 1 patient had synchronous contralateral stage IIIB disease treated with chemoradiation. EGFR-TKI were used as a 1 st line systemic therapy in $14(60.9 \%)$ patients, 2nd line following chemotherapy in 7 (30.4\%) patients and as third/fourth line therapy in 2 (8.6\%) patients. The EGFR-TKIs given were erlotinib, osimertinib and gefitinib in 15,5 , and 3 patients, respectively. Five patients had brain metastases prior to SBRT that were treated with whole-brain radiation therapy (WBRT), stereotactic radiosurgery (SRS) or resection, and were controlled. Eight patients received radiotherapy for subsequent brain metastases with WBRT (6 patients) and/or SRS (5 patients, 8 sessions). 
Table 1

Patient Characteristics

\begin{tabular}{|c|c|c|}
\hline variables & $\mathbf{N}$ & $\%$ \\
\hline Number of patients & 23 & \\
\hline \multicolumn{3}{|l|}{ Gender } \\
\hline Male & 2 & 8.7 \\
\hline Female & 21 & 91.3 \\
\hline Age (median) & \multicolumn{2}{|c|}{68 years (range, 33-89) } \\
\hline \multicolumn{3}{|l|}{ ECOG } \\
\hline 0 & 12 & 52.2 \\
\hline 1 & 9 & 39.1 \\
\hline 2 & 2 & 8.7 \\
\hline \multicolumn{3}{|l|}{ Smoking History } \\
\hline Never Smoker & 9 & 39.1 \\
\hline$<15$ pack-years & 6 & 26.1 \\
\hline >15 pack-years & 8 & 34.8 \\
\hline \multicolumn{3}{|l|}{ Contraindication to Surgery } \\
\hline Medically unfit & 2 & 8.7 \\
\hline Metastatic/Stage IV disease & 21 & 91.3 \\
\hline \multicolumn{3}{|l|}{ Stage } \\
\hline$|-| \mid$ & 1 (recurrent) & 4.35 \\
\hline III & 1 (recurrent) & 4.35 \\
\hline IV & 21 & 91.3 \\
\hline \multicolumn{3}{|l|}{ Brain Mets at Diagnosis } \\
\hline Yes & 5 & 21.7 \\
\hline No & 18 & 78.3 \\
\hline Central Lesion & 2 & 8.7 \\
\hline \multicolumn{3}{|c|}{ SBRT Total Dose (dose per fraction) } \\
\hline 50 Gy (10 Gy) & 19 & 82.6 \\
\hline 60 Gy (12 Gy) & 2 & 8.7 \\
\hline
\end{tabular}




\begin{tabular}{|c|c|c|}
\hline variables & $\mathbf{N}$ & $\%$ \\
\hline 50 Gy (5 Gy) & 1 & 4.35 \\
\hline 60 Gy (7.5 Gy) & 1 & 4.35 \\
\hline \multicolumn{3}{|l|}{ EGFR-TKI lines of systemic therapy } \\
\hline First Line & 14 & 60.9 \\
\hline Second Line & 7 & 30.4 \\
\hline Third/Forth line & 2 & 8.6 \\
\hline Histology & 23 & 100 \\
\hline \multicolumn{3}{|l|}{ Adenocarcinoma } \\
\hline \multicolumn{3}{|l|}{ EGFR Mutation Type } \\
\hline Exon 19 deletions & \multicolumn{2}{|c|}{$10($ single $=6 ;$ as co-mutation $=4)$} \\
\hline Exon 20/T790M & \multicolumn{2}{|c|}{$8($ single $=1 ;$ as co-mutation $=7)$} \\
\hline Exon 21 L858R substitutions & \multicolumn{2}{|c|}{$5($ single $=1 ;$ as co-mutation $=4)$} \\
\hline Others (exon 18, S768I) & \multicolumn{2}{|c|}{$3($ single $=1 ;$ as co-mutation $=2)$} \\
\hline Unavailable & \multicolumn{2}{|l|}{2} \\
\hline \multicolumn{3}{|l|}{ EGFR Inhibitor } \\
\hline Erlotinib & 15 & 65.2 \\
\hline Osimertinib & 5 & 21.8 \\
\hline Gefitinib & 3 & 13 \\
\hline Median number of systemic therapies (range) & \multicolumn{2}{|c|}{$3(1-5)$} \\
\hline Median Follow-up & \multicolumn{2}{|c|}{20 months (range, $4-102$ ) } \\
\hline
\end{tabular}

\section{Outcome:}

Median follow-up after SBRT was 20 months (range 4-102 months), and at the time of analysis, 8 patients were alive. The median duration of EGFR-TKI therapy was 26-months (range, 1-91 months). In 2 $(8.7 \%)$ patients, EGFR-TKI was discontinued due to poor tolerance and toxicity. SBRT dramatically altered the subsequent pattern of failure, with most patients progressed in new distant sites, involving bones in 5 $(21.7 \%)$ patients; distant lung in $4(17.4 \%)$, brain in three $(13 \%)$, liver in two $(8.7 \%)$, and adrenal in three patients (13\%) [Figure 1]. Only 2 of 23 patients (8.7\%) had initial progression within treated radiation field. The median OS was 31 months ( $95 \%$ confidence interval $(\mathrm{Cl}) 17.4-44.6$ months), and median PFS was 8 months ( $95 \% \mathrm{Cl} 5.7-10.4$ months) after completion of SBRT as determined from KM analysis. Actuarial 1-year OS and PFS were $78.3 \%$ and $34.8 \%$, respectively [Figure 2]. Median LCR was not reached; 
actuarial 5-year LCR was 52.4\%. 1-year OS for patients receiving gefitinib, erlotinib, and osimertinib were $33.3 \%, 93.3 \%$. and $60 \%$, respectively $(\mathrm{p}=0.1)$ [Figure 3]. Patients harboring EGFR-resistance mutations (S768I and T790M) [17] were trending to inferior OS than other EGFR mutations (median OS: 20 vs 31 months, 2-year OS $41.7 \%$ vs. $57.8 \%, p=0.2$ ) [Figure 4]. Patients who received EGFR-TKI as first- or secondline therapy had significantly better OS than patient receiving it as third/fourth lines (median OS 31 vs. 8 months, 1 -year OS $85.7 \%$ vs. $0 \%$, respectively, $p=0.01$ ) [Figure 4]. There was no difference in OS for patients with overlapping mutation $(p=0.9)$. Brain metastasis were treated with SRS/WBRT and did not affect survival $(p=0.8)$. Median lines of systemic therapies were three (range, 1-5). Switching to osimertinib, a third generation EGFR-TKI, was the most common salvage regimen at subsequent progression $(n=8)$ through EGFR-TKI, while 7-patients switched to chemotherapy or investigational agents/immunotherapy under protocol.

\section{Toxicity and ESAS Assessment:}

Toxicity and ESAS data are illustrated in Table 2. All patients completed planned treatment, and no acute SBRT-related grade 2-5 adverse effects were noted. Grade 2 pneumonitis was observed in $2(8.7 \%)$ patients at 3 and 6 months (both received erlotinib). Patient who developed pneumonitis at 3-months also received chemoradiation for stage IIIB disease. One patient developed treatment related rib fracture. The most common toxicities related to EGFR-TKI included grade 1-2 skin rash, diarrhea, neutropenia, fatigue, nausea/vomiting. All patient completed ESAS questionnaire. Overall, patients tolerated treatment well, with most common reported symptom of fatigue (21.7\%). Most patient reported excellent well-being (82.6\%) and no depression (82.6\%). On exploratory univariable analysis, we observed that patients who scored $\geq 5$ in fatigue (median OS: 18 vs 31 -months, 1 -yr OS $60 \%$ vs $78.6 \%, p=0.2$ ) and loss-of-appetite (8 vs 21 -months, 1 -yr OS $33.3 \%$ vs $81.3 \%, p=0.3$ ) were trending towards inferior overall survival. Of note, patient who scored $\geq 5$ on pain score did significantly better than the other group $(p=0.01)$. This finding could be related to better supportive care involvement in these patient cares, however, remains to be explored further. 
Table 2

Toxicity (CTCAE v.5) and Edmonton Symptom Assessment Scale (ESAS) Quality of Life Score

\begin{tabular}{|lll|}
\hline TOXICITY & NUMBER OF PATIENTS & $\%$ \\
\hline Grade 2 Pneumonitis & 2 & 8.7 \\
\hline Grade 2 chest wall toxicity/rib fracture & 1 & 4.3 \\
\hline ESAS Tiredness Scores & & \\
\hline 0 & 16 & 69.6 \\
\hline $1-5$ & 2 & 8.7 \\
\hline $6-10$ & 5 & 21.7 \\
\hline ESAS Pain Score & & \\
\hline 0 & 15 & 65.2 \\
\hline $1-5$ & 6 & 26.1 \\
\hline $6-10$ & 2 & 8.7 \\
\hline ESAS Lack of Appetite & & \\
\hline 0 & 16 & 69.6 \\
\hline $1-5$ & 5 & 21.7 \\
\hline $6-10$ & 2 & 8.7 \\
\hline ESAS Depression & & \\
\hline 0 & 19 & 82.6 \\
\hline $1-5$ & 3 & 13.1 \\
\hline $6-10$ & 1 & 4.3 \\
\hline ESAS Overall Wellbeing & & \\
\hline 0 & & \\
\hline $1-5$ & & \\
\hline $6-10$ & & \\
\hline
\end{tabular}

\section{Discussion}

For EGFR-mutated NSCLC, EGFR-TKIs shows dramatic initial response, however, acquired resistance is inevitable, and the initiation of new systemic therapy is the next therapeutic step $[2-4,18]$. Patients progressing through first-line systemic therapy exhibit poor survival and small advantage in PFS [19]. In 
select cases where initial disease progression is limited to dominant thoracic disease, SBRT can derive greater benefit in lengthening PFS than a change in systemic therapy. Here, in patients with EGFRmutated NSCLC on EGFR-TKI with intrathoracic oligoprogressive disease treated with SBRT, we demonstrated PFS of 8-months and excellent median duration of EGFR-TKI therapy of 26-months. The PFS and duration of initial systemic therapy in this series are comparable to first-line therapy published in literature, thus offer a promising treatment paradigm with comparable efficacy $[12,20]$.

EGFR-mutant NSCLC patients that progress through EGFR-TKIs experience initial oligoprogression predominantly $(50-80 \%)$ involving lungs $[9,11,21]$. These oligoprogressive sites harbor a population of TKI-resistant and dedifferentiated subclones with the potential to re-seed systemically leading to widespread disease progression [22, 23]. Aggressive SBRT to ablate these resistant subclones can delay progression and need to switch (or discontinue) therapy. While emerging evidence from oligometastatic disease shows upfront LCT delay progression and improve survival, there is little data about SBRT in patients that progressed through modern EGFR-TKI therapy [5-7]. A retrospective study of 23 EGFRmutant patients on 1st generation EGFR-TKIs demonstrated an initial median PFS of 10.3 months, however, in 10 patients that received subsequent LCT for oligoprogression, showed additional PFS benefit of 6.2 months [14]. Another retrospective study of 18 patients with EGFR-mutated NSCLC that acquired resistance to $1 \mathrm{st}$ generation TKIs received elective LCT with continued EGFR-TKI showed a prolonged PFS of 10 months and OS of 41 months with good tolerance [12]. Our study supports that lung SBRT in EGFRmutated NSCLC patients progressing through EGFR-TKI can extend median PFS by additional 8 months, and median OS by 31 months $[4,24]$. Despite patients in this study already had an initial progression prior to SBRT, and PFS was calculated from SBRT, results are still comparable to some studies that evaluated adjuvant EGFR-TKI alone in treatment naïve NSCLC [4, 24-26]. To put in perspective, osimertinib provides an 8-months PFS benefit compared to older generation TKIs in the FLAURA study [26]. However, this benefit is seen in a treatment naïve patient population. The benefit of SBRT in our study is in a population that has already showed resistance to targeted therapy through progression making an 8-months additional PFS benefit significant for this treatment group.

Our results also showed that SBRT enabled patients to effectively continue on EGFR-TKI therapy for a prolonged duration with median therapy duration of 26-months (1-85 months). This figure is longer than many historical studies using EGFR-TKI alone for recurrent and even some studies in adjuvant setting [12, 20]. Recently reported ADAURA study, a phase III, randomized placebo-controlled trial that showed resected EGFR-mutated NSCLC (stage IB-IIIA), demonstrated encouraging results with median duration of adjuvant osimertinib of 22 months [27]. This reiterate how local therapy may benefit in combination with targeted treatment.

Our study expands on the work of a recent observational study in which EGFR-mutated NSCLC patient treated with osimertinib, showed $80 \%$ patients developed progressive disease within the initially involved thoracic sites, most of which were a potential SBRT candidate [9]. Although this study brought forth an important concept to use SBRT to delay progression, no patients were actually treated with SBRT. Our study is among largest experiences in this patient population evaluating modern EGFR-TKIs plus SBRT 
for intrathoracic OPD. Our results demonstrated that lung SBRT dramatically alter the typical pattern of subsequent failures. Most common sites of initial failure following SBRT were distant, and only 2 patients $(8.7 \%)$ had initial recurrence within the treated site [Figure 1]. This contrasts with pattern of failure studies in literature for patients on EGFR-TKI, that showed approximately $50-80 \%$ had lungs as the initial site of progressive disease $[5,9,21]$.

With maturing evidence of combination of EGFR-TKIs plus SBRT, particularly with newer-generation TKI e.g. osimertinib, it is pragmatic to explore toxicity data. A phase II study with erlotinib and SBRT in metastatic NSCLC showed 29 grade 3-5 toxicities observed in 24 patients, four of which could be attributed to SBRT (pneumonitis and vertebral fracture) [13]. Some retrospective studies have shown higher rates of severe radiation pneumonitis with combination of radiotherapy to first-generation EGFRTKIs [28]. With careful patient selection (disease size and location) and precise planning and delivery of SBRT, dose to normal lung can be effectively reduced mitigating the risk of pneumonitis. Our patients tolerated treatment well with no treatment related death or dose limiting toxicity. Grade 2 pneumonitis was observed in two patients, while one developed treatment related grade 2 (rib fracture) chest wall toxicity. Patient reported ESAS outcome analysis showed good tolerance to therapy, with fatigue being most common symptom.

Given disease heterogeneity and relative rarity of presentation (EGFR-mutant, oligoprogressive on TKIs) designing a randomized trial will always be challenging and time consuming; and lack of a uniform comparator group will limit valid interpretation. Therefore, the evidence needs to be established with assemblage of data from institutional retrospective studies and small phase II trials. A single-arm phase II trial (NCT01941654) from China is evaluating preemptive LCT to residual metabolically active oligometastases in 34 patients with EGFR-mutant NSCLC who had an initial response to first-line TKI therapy. The fact that this study has only accrued 18/34 patients since 2013 underscores this difficulty with accruing large patient numbers in such study. A single arm, multicenter phase II study (NCT02314364) SBRT for stage IV oncogene-driven NSCLC receiving TKIs is ongoing. The target accrual is 30 patients between 2013-2021 (7-years), with primary outcome to study patterns of distant failures following SBRT. Preliminary report of an ongoing prospective, multicenter, randomized study (SINDAS Trial, NCT02893332) evaluating EGFR-TKIs \pm upfront SBRT in therapy naïve EGFR-mutant metastatic NSCLC patients showed that SBRT significantly improved PFS and OS compared to TKI alone [15]. The HALT trial (NCT03256981), is a randomized, multi-center, phase II/III study ongoing in UK, is the only ongoing trial directly evaluating the role of SBRT + TKI in patients with oligoprogressive oncogeneaddicted NSCLC $(n=110)$ [29].

There are several limitations of this study that should be acknowledged. First, this was a single institution study with relatively small number of patients. Most data evaluating role of SBRT in oligoprogressive EGFR-mutant NSCLC on TKIs is in the form of small single-institution experiences. The small target accrual of ongoing prospective studies over extended time periods emphasizes the complexity of such studies and relative rarity and heterogeneity of this clinical scenario, especially in context of newergeneration EGFR-TKIs. To the best of our knowledge, this study is still one of the largest series evaluating 
effectiveness of thoracic SBRT with modern EGFR-TKI in oligoprogressive EGFR-mutant NSCLC patients. Second, given the retrospective design there were no pre-defined inclusion criteria. However, at our institution we prospectively collect all data for lung cancer patients including toxicity and patient reported outcome. Last, superior outcome reported in this study could potentially be due to predominant women $(n=21,91.3 \%)$ in this study, and it has been shown that females fare better with treatment than males [30].

This study demonstrates the efficacy and safety of a novel therapy indication of thoracic SBRT in oligoprogressive EGFR-mutant NSCLC with EGFR-TKI prolonging PFS and OS and allowing continuation of targeted therapy longer than historic data for EGFR-TKI alone. More information will emerge after completion of ongoing prospective studies, until then retrospective evidence should be explored to establish more evidence.

\section{Abbreviations}

EGFR - epidermal growth factor receptor; NSCLC - non small cell lung cancer; SBRT - stereotactic body radiotherapy; OPD - oligoprogressive disease; TKI - Tyrosine kinase inhibitors; PFS - progression-free survival; OS - overall survival; ESAS - Edmonton Symptom Assessment Scale; RT - Radiotherapy; LCT Local cytoreductive therapy; PET - positron emission tomography; CT - computed tomography; GTV gross tumor volume; iGTV - internal target volume; IMRT - Intensity modulated radiotherapy; VMAT volumetric modulated radiotherapy; RECIST - Response Evaluation Criteria in Solid Tumor; LCR - local control rates; RTOG - radiation therapy oncology group; WBRT - whole-brain radiation therapy; SRS stereotactic radiosurgery

\section{Declarations}

Conflict of Interest: The authors declare that they have no competing interests

Conference Presented: Accepted for presentation at the ASTRO 2020 national meeting

Funding: This research did not receive any specific grant from funding agencies in the public, commercial, or not-for-profit sectors.

\section{Ethical Approval and Consent to participate:}

All patients signed informed consent for the treatment. Data were collected retrospectively from Moffitt Cancer Center IRB approved registry.

\section{Consent for publication:}

Not applicable 
Availability of supporting data:

The datasets in this study are not publicly available. Deidentified patient data can be provided on request and on completion of data sharing agreement between institutions.

\section{Competing interests:}

The authors declare that they have no competing interest

\section{Funding:}

This research did not receive any specific grant from funding agencies in the public, commercial, or notfor-profit sectors.

\section{Authors' contributions:}

Guarantor of integrity of the entire study - Stephen A. Rosenberg, Anupam Rishi; Study concepts and design - Stephen A. Rosenberg, Anupam Rishi; Literature research - Anupam Rishi, Stephen A. Rosenberg, Steven Sun, Ahmad M. Karimi, Austin J. Sim; Statistical analysis - Anupam Rishi, Stephen A. Rosenberg; Manuscript preparation - Anupam Rishi, Stephen A. Rosenberg, Jhanelle E Gray, Ahmad M. Karimi, Austin J. Sim, Bradford A. Perez, Steven Sun; Manuscript editing - Anupam Rishi, Stephen A. Rosenberg, Steven Sun, Ahmad M. Karimi, Austin J. Sim, Michael Shafique, Andreas Saltos, Jhanelle E Gray, Bradford A. Perez, Thomas J. Dilling

Acknowledgements: Not applicable.

\section{Authors' information:}

Affiliations: Department of Radiation Oncology, H. Lee Moffitt Cancer Center and Research Institute, Tampa, FL, USA; Morsani School of Medicine, University of South Florida Health, Tampa, Florida, USA; Department of Thoracic Oncology, H. Lee Moffitt Cancer Center and Research Institute, Tampa, FL, USA.

\section{References}

1. Consortium APG: AACR Project GENIE: Powering Precision Medicine through an International Consortium. Cancer Discov. 2017, 7:818-831. 10.1158/2159-8290.CD-17-0151

2. Mok TS, Wu YL, Ahn MJ, Garassino MC, Kim HR, Ramalingam SS, Shepherd FA, He Y, Akamatsu H, Theelen WS, Lee CK, Sebastian M, Templeton A, Mann H, Marotti M, Ghiorghiu S, Papadimitrakopoulou VA, Investigators A: Osimertinib or Platinum-Pemetrexed in EGFR T790MPositive Lung Cancer. N Engl J Med. 2017, 376:629-640. 10.1056/NEJMoa1612674

3. Mok TS, Wu YL, Thongprasert S, Yang CH, Chu DT, Saijo N, Sunpaweravong P, Han B, Margono B, Ichinose Y, Nishiwaki Y, Ohe Y, Yang JJ, Chewaskulyong B, Jiang H, Duffield EL, Watkins CL, Armour 
AA, Fukuoka M: Gefitinib or carboplatin-paclitaxel in pulmonary adenocarcinoma. N Engl J Med. 2009, 361:947-957. 10.1056/NEJMoa0810699

4. Rosell R, Carcereny E, Gervais R, Vergnenegre A, Massuti B, Felip E, Palmero R, Garcia-Gomez R, Pallares C, Sanchez JM, Porta R, Cobo M, Garrido P, Longo F, Moran T, Insa A, De Marinis F, Corre R, Bover I, Illiano A, Dansin E, de Castro J, Milella M, Reguart N, Altavilla G, Jimenez U, Provencio M, Moreno MA, Terrasa J, Munoz-Langa J, Valdivia J, Isla D, Domine M, Molinier O, Mazieres J, Baize N, Garcia-Campelo R, Robinet G, Rodriguez-Abreu D, Lopez-Vivanco G, Gebbia V, Ferrera-Delgado L, Bombaron P, Bernabe R, Bearz A, Artal A, Cortesi E, Rolfo C, Sanchez-Ronco M, Drozdowskyj A, Queralt C, de Aguirre I, Ramirez JL, Sanchez JJ, Molina MA, Taron M, Paz-Ares L, Spanish Lung Cancer Group in collaboration with Groupe Francais de P-C, Associazione Italiana Oncologia T: Erlotinib versus standard chemotherapy as first-line treatment for European patients with advanced EGFR mutation-positive non-small-cell lung cancer (EURTAC): a multicentre, open-label, randomised phase 3 trial. Lancet Oncol. 2012, 13:239-246. 10.1016/S1470-2045(11)70393-X

5. Gomez DR, Tang C, Zhang J, Blumenschein GR, Jr., Hernandez M, Lee JJ, Ye R, Palma DA, Louie AV, Camidge DR, Doebele RC, Skoulidis F, Gaspar LE, Welsh JW, Gibbons DL, Karam JA, Kavanagh BD, Tsao AS, Sepesi B, Swisher SG, Heymach JV: Local Consolidative Therapy Vs. Maintenance Therapy or Observation for Patients With Oligometastatic Non-Small-Cell Lung Cancer: Long-Term Results of a Multi-Institutional, Phase II, Randomized Study. J Clin Oncol. 2019, 37:1558-1565.

10.1200/JC0.19.00201

6. Palma DA, Olson R, Harrow S, Gaede S, Louie AV, Haasbeek C, Mulroy L, Lock M, Rodrigues GB, Yaremko BP, Schellenberg D, Ahmad B, Griffioen G, Senthi S, Swaminath A, Kopek N, Liu M, Moore K, Currie S, Bauman GS, Warner A, Senan S: Stereotactic ablative radiotherapy versus standard of care palliative treatment in patients with oligometastatic cancers (SABR-COMET): a randomised, phase 2, open-label trial. Lancet. 2019, 393:2051-2058. 10.1016/S0140-6736(18)32487-5

7. Phillips R, Shi WY, Deek M, Radwan N, Lim SJ, Antonarakis ES, Rowe SP, Ross AE, Gorin MA, Deville C, Greco SC, Wang H, Denmeade SR, Paller CJ, Dipasquale S, DeWeese TL, Song DY, Wang H, Carducci MA, Pienta KJ, Pomper MG, Dicker AP, Eisenberger MA, Alizadeh AA, Diehn M, Tran PT: Outcomes of Observation vs Stereotactic Ablative Radiation for Oligometastatic Prostate Cancer: The ORIOLE Phase 2 Randomized Clinical Trial. JAMA Oncol. 2020. 10.1001/jamaoncol.2020.0147

8. Owen D, Olivier KR, Mayo CS, Miller RC, Nelson K, Bauer H, Brown PD, Park SS, Ma DJ, Garces YI: Outcomes of stereotactic body radiotherapy (SBRT) treatment of multiple synchronous and recurrent lung nodules. Radiat Oncol. 2015, 10:43. 10.1186/s13014-015-0340-9

9. Guo T, Ni J, Yang X, Li Y, Li Y, Zou L, Wang S, Liu Q, Chu L, Chu X, Li S, Ye L, Zhu Z: Pattern of Recurrence Analysis in Metastatic EGFR-Mutant NSCLC Treated with Osimertinib: Implications for Consolidative Stereotactic Body Radiation Therapy. Int J Radiat Oncol Biol Phys. 2020, 107:62-71. 10.1016/j.jijrobp.2019.12.042

10. Schmid S, Klingbiel D, Aeppli S, Britschgi C, Gautschi O, Pless M, Rothschild S, Wannesson L, Janthur W, Foerbs D, Demmer I, Jochum W, Fruh M: Patterns of progression on osimertinib in EGFR T790M 
positive NSCLC: A Swiss cohort study. Lung Cancer. 2019, 130:149-155.

10.1016/j.lungcan.2019.02.020

11. Patel SH, Rimner A, Foster A, Zhang Z, Woo KM, Yu HA, Riely GJ, Wu AJ: Patterns of initial and intracranial failure in metastatic EGFR-mutant non-small cell lung cancer treated with erlotinib. Lung Cancer. 2017, 108:109-114. 10.1016/j.lungcan.2017.03.010

12. Yu HA, Sima CS, Huang J, Solomon SB, Rimner A, Paik P, Pietanza MC, Azzoli CG, Rizvi NA, Krug LM, Miller VA, Kris MG, Riely GJ: Local therapy with continued EGFR tyrosine kinase inhibitor therapy as a treatment strategy in EGFR-mutant advanced lung cancers that have developed acquired resistance to EGFR tyrosine kinase inhibitors. J Thorac Oncol. 2013, 8:346-351.

10.1097/JTO.0b013e31827e1f83

13. lyengar P, Kavanagh BD, Wardak Z, Smith I, Ahn C, Gerber DE, Dowell J, Hughes R, Abdulrahman R, Camidge DR, Gaspar LE, Doebele RC, Bunn PA, Choy H, Timmerman R: Phase II trial of stereotactic body radiation therapy combined with erlotinib for patients with limited but progressive metastatic non-small-cell lung cancer. J Clin Oncol. 2014, 32:3824-3830. 10.1200/JC0.2014.56.7412

14. Weickhardt AJ, Scheier B, Burke JM, Gan G, Lu X, Bunn PA, Jr., Aisner DL, Gaspar LE, Kavanagh BD, Doebele RC, Camidge DR: Local ablative therapy of oligoprogressive disease prolongs disease control by tyrosine kinase inhibitors in oncogene-addicted non-small-cell lung cancer. J Thorac Oncol. 2012, 7:1807-1814. 10.1097/JTO.0b013e3182745948

15. Wang $X$, Zeng M: First-line tyrosine kinase inhibitor with or without aggressive upfront local radiation therapy in patients with EGFRm oligometastatic non-small cell lung cancer: Interim results of a randomized phase III, open-label clinical trial (SINDAS) (NCT02893332). J Clin Oncol. 2020, 38:9508-9508. 10.1200/JC0.2020.38.15_suppl.9508

16. Bezjak A, Paulus R, Gaspar LE, Timmerman RD, Straube WL, Ryan WF, Garces YI, Pu AT, Singh AK, Videtic GM, McGarry RC, lyengar P, Pantarotto JR, Urbanic JJ, Sun AY, Daly ME, Grills IS, Sperduto P, Normolle DP, Bradley JD, Choy H: Safety and Efficacy of a Five-Fraction Stereotactic Body Radiotherapy Schedule for Centrally Located Non-Small-Cell Lung Cancer: NRG Oncology/RTOG 0813 Trial. J Clin Oncol. 2019, 37:1316-1325. 10.1200/JC0.18.00622

17. Graham RP, Treece AL, Lindeman NI, Vasalos P, Shan M, Jennings LJ, Rimm DL: Worldwide Frequency of Commonly Detected EGFR Mutations. Arch Pathol Lab Med. 2018, 142:163-167. 10.5858/arpa.2016-0579-CP

18. Camidge DR, Pao W, Sequist LV: Acquired resistance to TKIs in solid tumours: learning from lung cancer. Nat Rev Clin Oncol. 2014, 11:473-481. 10.1038/nrclinonc.2014.104

19. Tassinari D, Scarpi E, Sartori S, Drudi F, Castellani C, Carloni F, Tombesi P, Lazzari-Agli L: Noninferiority trials in second-line treatments of nonsmall cell lung cancer: a systematic review of literature with meta-analysis of phase III randomized clinical trials. Am J Clin Oncol. 2012, 35:593599. 10.1097/COC.0b013e31822dfd13

20. Kelly K, Altorki NK, Eberhardt WE, O'Brien ME, Spigel DR, Crino L, Tsai CM, Kim JH, Cho EK, Hoffman PC, Orlov SV, Serwatowski P, Wang J, Foley MA, Horan JD, Shepherd FA: Adjuvant Erlotinib Versus 
Placebo in Patients With Stage IB-IIIA Non-Small-Cell Lung Cancer (RADIANT): A Randomized, Double-Blind, Phase III Trial. J Clin Oncol. 2015, 33:4007-4014. 10.1200/JC0.2015.61.8918

21. Al-Halabi H, Sayegh K, Digamurthy SR, Niemierko A, Piotrowska Z, Willers H, Sequist LV: Pattern of Failure Analysis in Metastatic EGFR-Mutant Lung Cancer Treated with Tyrosine Kinase Inhibitors to Identify Candidates for Consolidation Stereotactic Body Radiation Therapy. J Thorac Oncol. 2015, 10:1601-1607. 10.1097/JT0.0000000000000648

22. Jamal-Hanjani M, Wilson GA, McGranahan N, Birkbak NJ, Watkins TBK, Veeriah S, Shafi S, Johnson DH, Mitter R, Rosenthal R, Salm M, Horswell S, Escudero M, Matthews N, Rowan A, Chambers T, Moore DA, Turajlic S, Xu H, Lee SM, Forster MD, Ahmad T, Hiley CT, Abbosh C, Falzon M, Borg E, Marafioti T, Lawrence D, Hayward M, Kolvekar S, Panagiotopoulos N, Janes SM, Thakrar R, Ahmed A, Blackhall F, Summers Y, Shah R, Joseph L, Quinn AM, Crosbie PA, Naidu B, Middleton G, Langman G, Trotter S, Nicolson M, Remmen H, Kerr K, Chetty M, Gomersall L, Fennell DA, Nakas A, Rathinam S, Anand G, Khan S, Russell P, Ezhil V, Ismail B, Irvin-Sellers M, Prakash V, Lester JF, Kornaszewska M, Attanoos R, Adams H, Davies H, Dentro S, Taniere P, O'Sullivan B, Lowe HL, Hartley JA, Iles N, Bell H, Ngai Y, Shaw JA, Herrero J, Szallasi Z, Schwarz RF, Stewart A, Quezada SA, Le Quesne J, Van Loo P, Dive C, Hackshaw A, Swanton C, Consortium TR: Tracking the Evolution of Non-Small-Cell Lung Cancer. N Engl J Med. 2017, 376:2109-2121. 10.1056/NEJMoa1616288

23. Doebele RC, Pilling AB, Aisner DL, Kutateladze TG, Le AT, Weickhardt AJ, Kondo KL, Linderman DJ, Heasley LE, Franklin WA, Varella-Garcia M, Camidge DR: Mechanisms of resistance to crizotinib in patients with ALK gene rearranged non-small cell lung cancer. Clin Cancer Res. 2012, 18:1472-1482. 10.1158/1078-0432.CCR-11-2906

24. Zhou C, Wu YL, Chen G, Feng J, Liu XQ, Wang C, Zhang S, Wang J, Zhou S, Ren S, Lu S, Zhang L, Hu C, Hu C, Luo Y, Chen L, Ye M, Huang J, Zhi X, Zhang Y, Xiu Q, Ma J, Zhang L, You C: Erlotinib versus chemotherapy as first-line treatment for patients with advanced EGFR mutation-positive non-smallcell lung cancer (OPTIMAL, CTONG-0802): a multicentre, open-label, randomised, phase 3 study. Lancet Oncol. 2011, 12:735-742. 10.1016/S1470-2045(11)70184-X

25. Wu YL, Cheng Y, Zhou X, Lee KH, Nakagawa K, Niho S, Tsuji F, Linke R, Rosell R, Corral J, Migliorino MR, Pluzanski A, Sbar El, Wang T, White JL, Nadanaciva S, Sandin R, Mok TS: Dacomitinib versus gefitinib as first-line treatment for patients with EGFR-mutation-positive non-small-cell lung cancer (ARCHER 1050): a randomised, open-label, phase 3 trial. Lancet Oncol. 2017, 18:1454-1466. 10.1016/S1470-2045(17)30608-3

26. Soria JC, Ohe Y, Vansteenkiste J, Reungwetwattana T, Chewaskulyong B, Lee KH, Dechaphunkul A, Imamura F, Nogami N, Kurata T, Okamoto I, Zhou C, Cho BC, Cheng Y, Cho EK, Voon PJ, Planchard D, Su WC, Gray JE, Lee SM, Hodge R, Marotti M, Rukazenkov Y, Ramalingam SS, Investigators F: Osimertinib in Untreated EGFR-Mutated Advanced Non-Small-Cell Lung Cancer. N Engl J Med. 2018, 378:113-125. 10.1056/NEJMoa1713137

27. Roy S. Herbst, Masahiro Tsuboi, Thomas John, Christian Grohé, Margarita Majem, Jonathan Wade Goldman, Sang-We Kim, Dominika Marmol, Yuri Rukazenkov, Wu Y-L: Osimertinib as adjuvant therapy in patients (pts) with stage IB-IIIA EGFR mutation positive (EGFRm) NSCLC after complete 
tumor resection: ADAURA. J Clin Oncol 38: 2020 (suppl; abstr LBA5). 2020.

10.1200/JC0.2020.38.18_suppl.LBA5

28. Zhuang H, Yuan Z, Chang JY, Wang J, Pang Q, Zhao L, Wang P: Radiation pneumonitis in patients with non--small-cell lung cancer treated with erlotinib concurrent with thoracic radiotherapy. $J$ Thorac Oncol. 2014, 9:882-885. 10.1097/JT0.0000000000000126

29. McDonald F, Hanna GG: Oligoprogressive Oncogene-addicted Lung Tumours: Does Stereotactic Body Radiotherapy Have a Role? Introducing the HALT Trial. Clin Oncol (R Coll Radiol). 2018, 30:1-4. 10.1016/j.clon.2017.10.013

30. International Early Lung Cancer Action Program I, Henschke Cl, Yip R, Miettinen OS: Women's susceptibility to tobacco carcinogens and survival after diagnosis of lung cancer. JAMA. 2006, 296:180-184. 10.1001/jama.296.2.180

\section{Figures}




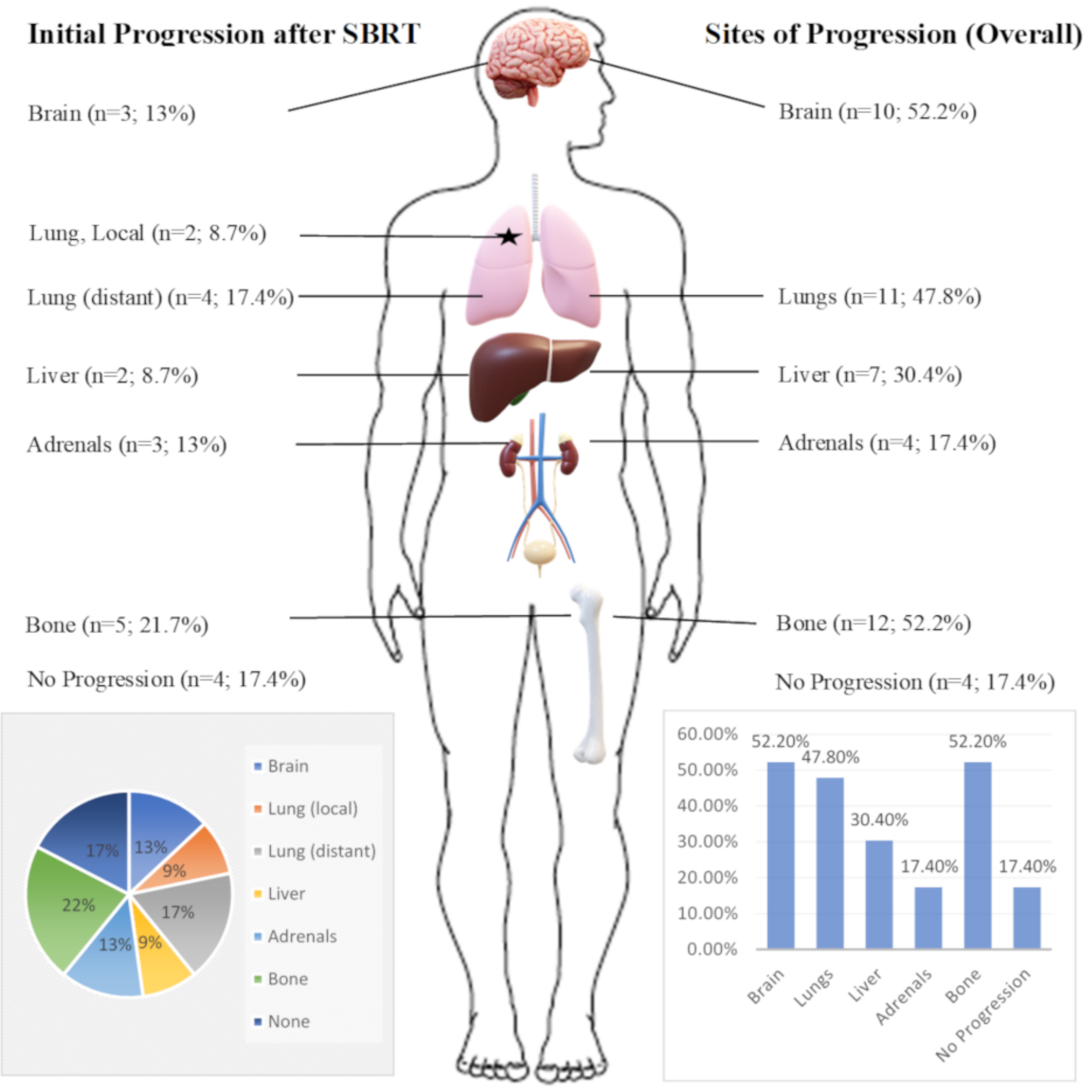

\section{Figure 1}

Schematic diagram showing site of initial and overall progression after SBRT 

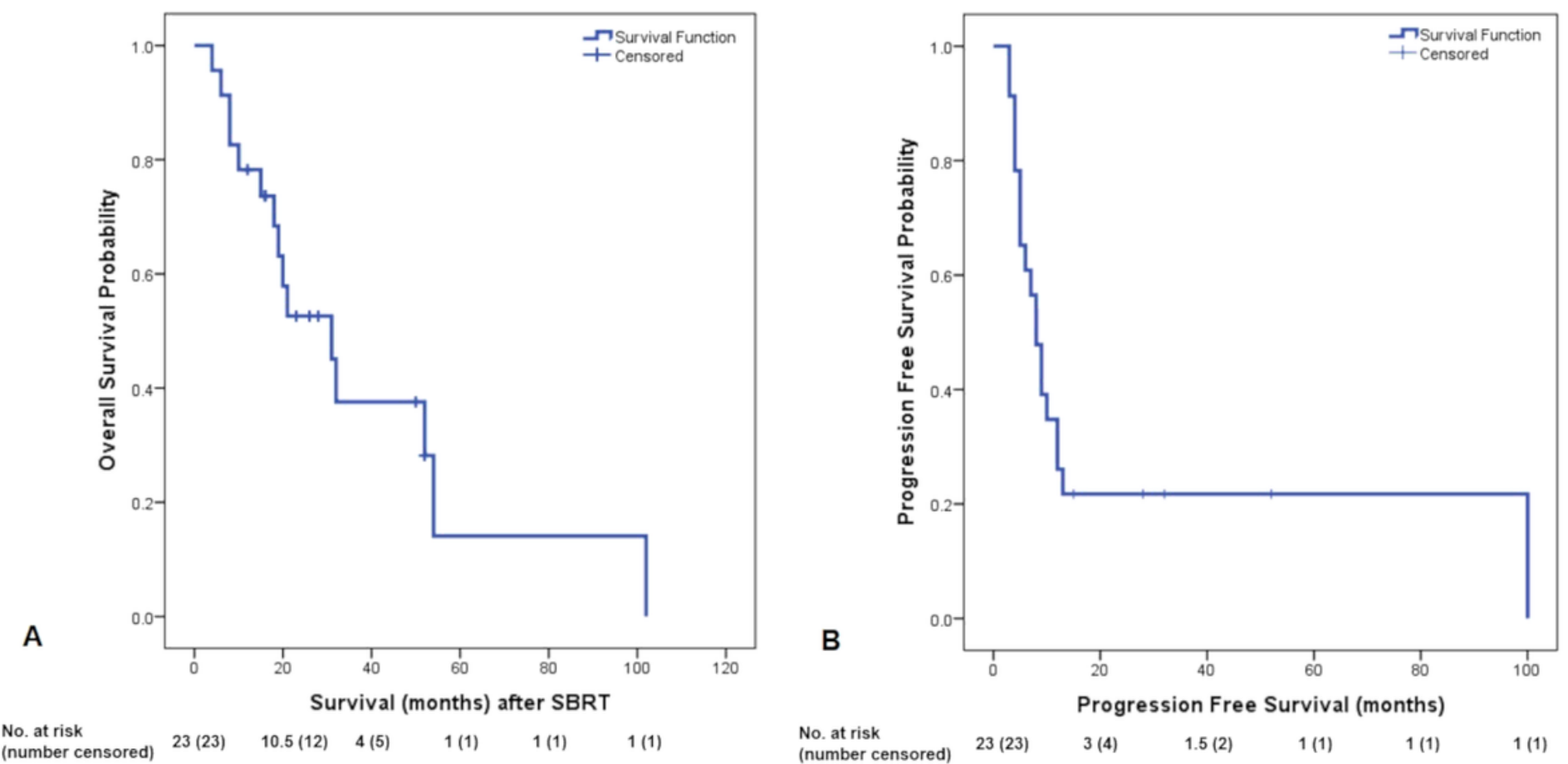

\section{Figure 2}

Kaplan-Meier estimate showing (A) overall survival curve (median OS 31 months ( $95 \% \mathrm{Cl} 17.4-44.6$ months) 1-year OS 78.3\%) (B) progression free survival (median PFS 8 months (95\% Cl $5.7-10.4$ months), 1-year PFS 34.8\%) 


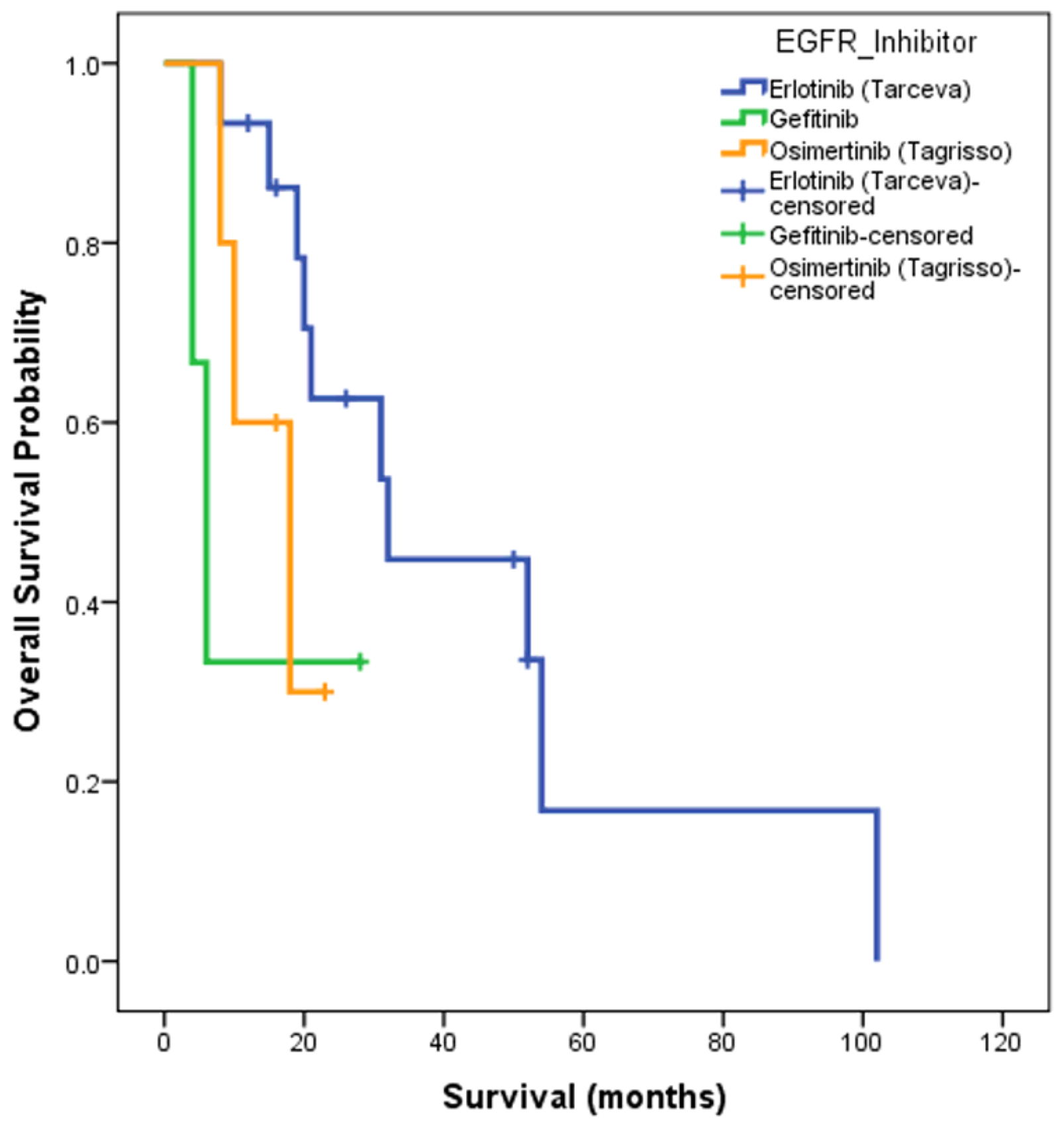

No. at risk

(Number censored)

Erlotinib

Gefitinib

15 (15)

3 (3)

$9.5(10)$

4 (5)

1 (1)

1 (1)

1 (1)

0 (0)

Osimertinib

5 (5)

1 (1)

0 (0)

0 (0)

0 (0)

0 (0)

$0(0) \quad 0(0)$

$0(0)$

0 (0)

$0(0)$

Figure 3

The Kaplan-Meier curve shows the overall survival for patients receiving gefitinib (1-yr OS - 33.3\%) vs erlotinib (93.3\%) vs osimertinib $(60 \%)(p=0.1)$. 

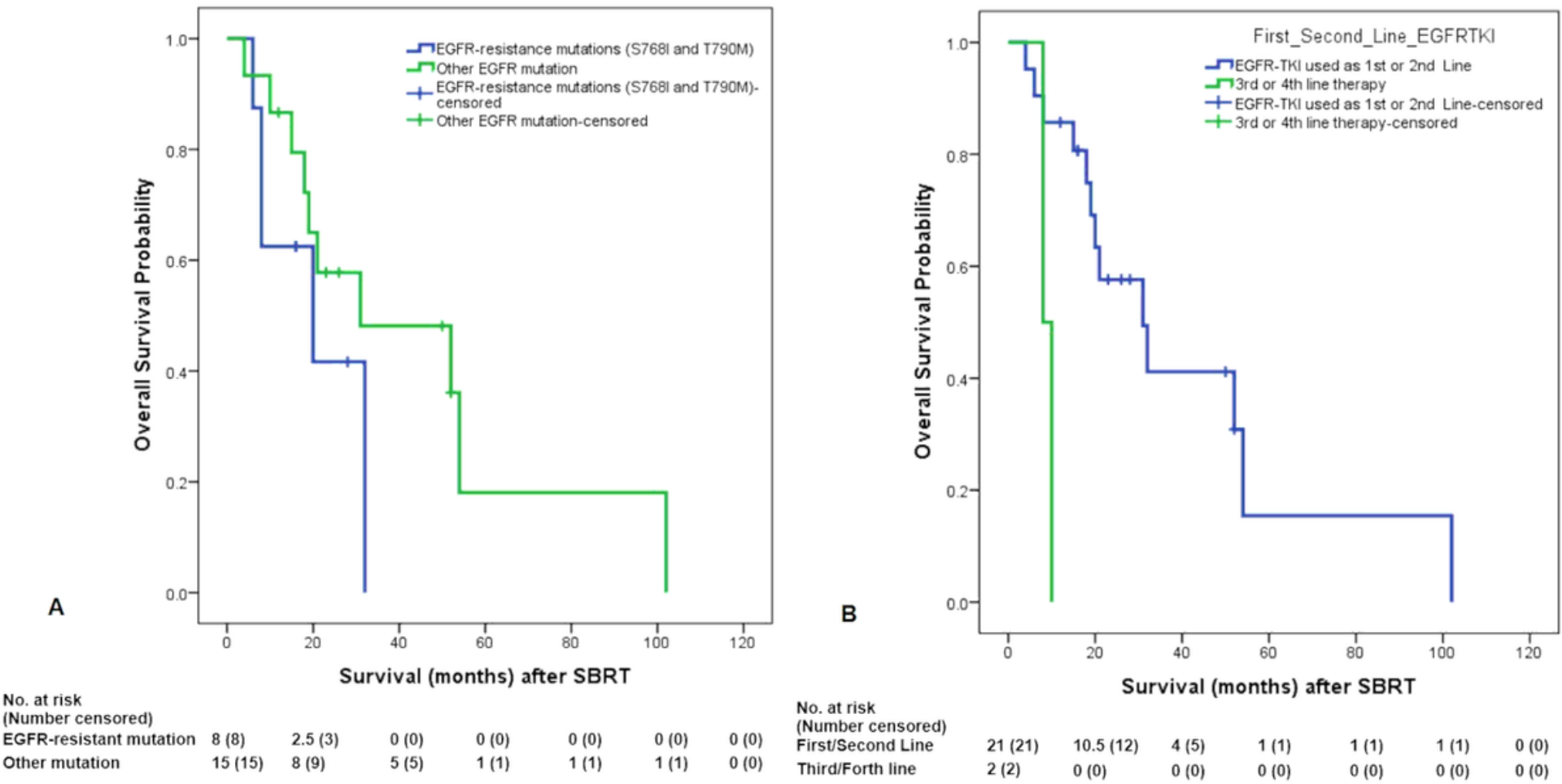

Figure 4

The Kaplan-Meier curve shows the overall survival for (A) patient harboring EGFR-resistance mutations (S768I and T790M) vs other EGFR mutations types (2-year OS 41.7 vs $57.8 \%, p=0.2$, respectively) (B) Patient that received EGFR-TKI as first- or second-line therapy vs. third- or fourth-line ((median OS 31 vs. 8 months, 1 year OS $85.7 \%$ vs. $0 \%$, respectively, $p=0.01$ ).

\section{Supplementary Files}

This is a list of supplementary files associated with this preprint. Click to download.

- SupplementaryTable1.docx 